\title{
Invasive electrophysiological study in the Jervell and Lange-Nielsen syndrome
}

Sir,

In a recent case report $(B r$ Heart $\mathcal{F} 1981$; 45: 225-9) Hartzler and Osborn, recording bipolar right ventricular electrograms in a case of the Jervell-LangeNielsen syndrome, observed late and bizarre waveforms prolonging abnormally the repolarisation phase. They think that these alterations may represent "part of the ' $T$ wave', or possibly the intracardiac counterpart of the ' $U$ wave'." We can confirm this observation and also the hypothesis that these abnormal waveforms correspond to the $U$ wave of the surface electrocardiogram. We recorded monophasic action potentials by suction electrocatheter in 10 cases of the long QT syndrome with severe ventricular arrhythmias, of which eight were acquired and two idiopathic: all showed asynchronous ventricular repolarisation. ${ }^{1}$ Potentials recorded in different areas of the right ventricle showed large and pathological differences in duration (from 100 to $270 \mathrm{~ms}$ ) and the longest showed obvious "humps" towards the end of repolarisation. When the "humps" were wide enough they were able to trigger focal re-excitation, that is, isolated ventricular extrasystoles and/or "torsades de pointe". These "humps" appear to correspond to pathological $U$ waves on the surface electrocardiogram. ${ }^{1-3}$ Our "humps" therefore correspond to the phenomena observed by Hartzler and Osborn buஜ they are much more evident and thus their interpreta음 tion is much easier.

We agree that in doubtful cases of the long QT syndrome electrophysiological study is helpful bue think that simultaneous monophasic action potentia recordings are important.

Giuseppe Botti, Vincenzo Bonatti,

Division of Cardiology,

Ospedali Riuniti di Parma,

Parma, Italy.

\section{References}

1 Bonatti V, Rolli A, Botti G. Recording of monophasic action potentials of the right ventricle in long QT3 sindromes complicated by severe ventricular arrhythmias? Eur Heart $\mathcal{f}$ (in press).

2 Bonatti V, Pavarani A, Botti G. Peculiar alterations of right ventricular monophasic action potential in a case of prolonged QT and electrical alternation of the $\mathrm{U}$ wave (abstract). Trans Eur Soc Cardiol 1978; 1: 174.

3 Bonatti V, Finardi A, Botti G. Enregistrement des potentiels d'action monophasiques du ventricule droi dans un case de QT long et alternance isolée de l'onde U. Arch Mal Coeur 1979; 72: 1180-6. 